\title{
O professor e a educação inclusiva: analisando a realidade escolar e formação com enfoque na perspectiva do desenho universal para a aprendizagem (DUA)
}

The teacher and inclusive education: analyzing school reality and training with a

focus on the perspective of universal design for learning (UDL)

Alessandra Boldrini Monechi

Luana Guisso

Resumo: Este estudo é um recorte da dissertação de mestrado "A Formação do Professor na Perspectiva do Desenho Universal para a Aprendizagem (DUA)" e tem como objetivo investigar a contribuição da aproximação das práticas pedagógicas de educadores da classe regular com aquelas voltadas para a inclusão do aluno públicoalvo da educação especial, numa Escola Estadual de Ensino Fundamental e Médio localizada no município de Linhares/ES. O presente estudo de caso foi realizado por meio de levantamento e análise de dados quantitativos de natureza descritiva, para este fim foi aplicado um questionário online aos sujeitos da pesquisa, visando conhecer não só suas experiências pedagógicas, acerca da educação inclusiva no locus da pesquisa, mas também suas demandas, anseios e expectativas. A partir da análise dos resultados, é possível perceber indícios de um cenário favorável para trabalhar com a abordagem do Desenho Universal para a Aprendizagem como possibilidade de inclusão escolar nesta escola, tendo em vista o elevado percentual de manifestações positivas sinalizando o desejo dos profissionais por processos formativos para a educação especial.

Palavras-chave: Educação. Educação Inclusiva. Formação Continuada. Desenho Universal para a Aprendizagem.

Abstract: This study is an excerpt from the master's dissertation "Teacher Education in the Perspective of Universal Design for Learning (UDL)" and aims to investigate the contribution of the approach of the pedagogical practices of educators of the regular class with those aimed at the inclusion of the target audience of special education, in a State School of Elementary and Secondary Education located in the municipality of Linhares / ES. The present case study was carried out by means of a survey and analysis of quantitative data of a descriptive nature, for this purpose an online questionnaire was applied to the research subjects, aiming to know not only their pedagogical experiences, about inclusive education in the research locus, but also their demands, desires and expectations. From the analysis of the results, it is possible to perceive evidence of a favorable scenario to work with the approach of Universal Design for Learning as a possibility of school inclusion in this school, in view of the high percentage of positive manifestations signaling the professionals' desire for processes training courses for special education.

Keywords: Education. Inclusive education. Continuing Education. Universal Learning Design. 


\section{Introdução}

A inclusão escolar se fortaleceu, especialmente, a partir da segunda metade da década de 90, com a difusão da Declaração de Salamanca (1994), elaborada pela Organização das Nações Unidas para a Educação, a Ciência e a Cultura (Unesco). A Declaração preconiza que crianças e jovens com necessidades educativas especiais precisam ter acesso às escolas regulares, que a elas devem se adequar por meio de uma pedagogia centrada na criança, capaz suprir essas necessidades, uma vez que tais escolas constituem os meios propícios ao combate de atitudes discriminatórias, construindo uma sociedade inclusiva e atingindo a educação para todos (UNESCO, 1994).

A partir de então, tornou-se um paradigma educacional fundamentado nos direitos humanos. Contudo, considerando que cada estudante possui suas maneiras e tempos de aprendizagem individuais e que as unidades e redes de ensino possuem seu público com essa imensa diversidade, além do fato de, muitas vezes, desconsiderarem as diferenças existentes entre os estudantes, buscando padronizar as aprendizagens, refletindo no paradoxo inclusão/exclusão, torna-se relevante pensar em uma mudança visando contemplar todos os alunos, especialmente aqueles que demandam maior apoio no processo educacional, ofertando, assim, uma educação inclusiva de fato.

A principal característica da educação inclusiva é ofertar o ensino para todos, prezando pela qualidade do ensino e pela permanência de todos os educandos na escola. Sendo assim, o trabalho na perspectiva da inclusão é aquele em que atende à diversidade de todos os alunos, levando-se em conta a subjetividade de cada um, respeitando o estudante, suas singularidades, suas limitações, seu modo de aprender, além de honrar o tempo de cada indivíduo, e, acima de tudo, acreditar no potencial que o estudante tem. Isto posto, é importante compreender a significação de uma escola reflexiva:

Acreditamos que, se quisermos uma escola que atenda à diversidade, ou seja, uma escola inclusiva, precisamos pensar com o outro, precisamos de um processo longo e constante de reflexão-ação-crítica, com os profissionais que fazem 0 ato educativo acontecer. Se quisermos mudanças significativas nas práticas convencionais de ensino, precisamos pensar a 
formação continuada dos educadores (JESUS, ALMEIDA, SOBRINHO, 2005, p.1).

Trabalhar de maneira inclusiva torna-se, portanto, um desafio para a comunidade escolar, tendo em conta a demanda de uma rede colaborativa estruturada, refletindo na necessidade formativa dos envolvidos, uma vez que aprendizagem e formação são processos que acontecem de maneira contínua.

Nesse sentido, os saberes dos docentes devem ser organizados sob o viés da heterogeneidade, considerando uma perspectiva inclusiva. A equipe escolar precisa, assim, disponibilizar espaços educacionais adequados aos discentes, considerando suas peculiaridades e tempos de aprendizagem, de modo a estimular seu desenvolvimento.

Diante disso, no presente artigo, buscamos investigar acerca da aproximação das práticas pedagógicas de educadores da classe regular com aquelas voltadas para a inclusão do aluno público-alvo da educação especial, em uma Escola Estadual de Ensino Fundamental.

\section{O Desenho Universal para a Aprendizagem}

O Desenho Universal para a Aprendizagem (DUA) surgiu na década de 90, com apoio do Departamento de Educação dos Estados Unidos, elaborado por um grupo de pesquisadores, liderado por David Rose e Anne Meyer, do Center for Applied Special Technology (CAST), em Massachusetts (ZERBATO; MENDES, 2018, p. 150). A ideia central do DUA é proporcionar uma abordagem educacional mais apropriada ao princípio constitucional (e universal) de que todos têm o direito à educação, atendendo às especificidades de pessoas que apresentam alguma necessidade especial de aprendizagem.

Sabendo que a diversidade não é exceção e sim norma e que os sujeitos aprendem de maneiras diversas, o Desenho Universal para Aprendizagem se apresenta como um conjunto de possibilidades - materiais flexíveis, técnicas e estratégias que busca ampliar a aprendizagem de alunos com ou sem deficiência. O objetivo é atingir assim, um número maior possível de alunos, universalizando, portanto, a aprendizagem. Os alunos são diferentes na maneira como percebem e compreendem a informação que lhes é apresentada. São diferenças sócio culturais, econômicas, diferentes idiomas, alunos com deficiências - intelectual, motora e sensorial. 
Atentos a essa realidade, a diversidade deve estar contemplada na maneira como o conteúdo é apresentado e nas múltiplas formas de representá-lo, na ampliação de oportunidades de ação e expressão dos alunos e no desenvolvimento de estratégias que garantam o envolvimento dos atores da aprendizagem (MANUAL DUA, p. 3) ${ }^{1}$.

Assim, a abordagem do DUA busca ampliar as oportunidades para o desenvolvimento de cada estudante a partir de um contínuo planejamento pedagógico. E, ainda, de acordo com Pletsch, Souza e Orleans (2017, p. 272), "As diretrizes desse conceito indicam a customização de recursos e estratégias em sala de aula para efetivar a aprendizagem de todos".

Segundo Zerbato e Mendes (2018, p. 150), o DUA tem como objetivo auxiliar educadores e demais profissionais a adotarem formas de ensino e aprendizagem adequados, escolhendo e desenvolvendo materiais e métodos eficientes e aprimorados para avaliar o progresso de todos os estudantes. A reformulação dos currículos escolares visando contemplar os princípios do DUA e da educação para todos, torna-se essencial, visto que o currículo deve ser percebido como representação das especificidades, assim como posto por Prais e Rosa (2014, p. 367):

a escola, que fundamenta suas práticas no desenho universal, compreende o currículo como representação das especifidades (sic) de todas as crianças, o qual é percebido na necessidade de flexibilização e planificação das necessidades de aprendizagens de um grupo heterogêneo que possuímos em sala de aula.

Não se trata, apenas, de adaptar conteúdos ou materiais didáticos, mas sim de idealizar e de planejar os recursos pedagógicos, de forma que possam contemplar o maior número de estudantes possível, assim como exemplificado por Zerbato e Mendes (2018, p. 150):

Ao elaborar materiais concretos para o aprendizado de conteúdos matemáticos para um aluno cego, por exemplo, tal recurso, normalmente, é pensado e adaptado para os alunosalvo da turma, porém, na perspectiva do DUA, o mesmo material pode ser utilizado por todos da sala de aula, de modo

\footnotetext{
${ }^{1}$ Desenho Universal para Livros Didáticos. Manual do Desenho Universal para Aprendizagem elaborado pelo "Movimento Down". Não disponibilizado o ano de publicação. Disponível em http://www.movimentodown.org.br/wp-content/uploads/2015/08/Manual-FINAL-bibliografia.pdf. Acesso em: 09 de fevereiro 2019.
} 
a beneficiar outros estudantes na compreensão dos conteúdos ensinados.

Tais práticas permitem englobar as especificidades diversas existentes em um espaço escolar, impactando na melhoria do desenvolvimento de cada educando, posto que toda pessoa tem direito de ter acesso ao conhecimento, de estudar e de buscar o melhor para si. À vista disso, Pletsch, Souza e Orleans (2017, p. 273), refletem que:

o conceito de desenho universal na aprendizagem pode representar um avanço no processo de escolarização de pessoas com deficiências, na medida em que possibilita acesso de todos ao currículo geral, diferentemente de épocas anteriores, em que o currículo para alunos com deficiência era diferente daquele oferecido aos demais alunos.

Diante disso, a metodologia do DUA possibilita a descontinuidade do formato tradicional da sala de aula do ensino regular, visando contribuir para um modelo educacional mais atrativo, com vistas a atender tanto as especificidades de pessoas com deficiência quanto as dos demais estudantes, endossando, assim, o compromisso de garantir a equidade na educação.

Costa e Pacheco (2018) recorrem a CAST $^{2}$ (2011) ao afirmar que três princípios norteiam o DUA, a saber: o primeiro deles está baseado em proporcionar meios múltiplos de representação (o "quê" da aprendizagem), ou seja, a apresentação do conteúdo deve acontecer por meio de diferentes vias, como por exemplo, quando são utilizadas várias formas de representação para um mesmo conceito, uma vez que os educandos diferem na maneira de compreender a informação apresentada, seja por necessidades específicas ou por individualidade cognitiva. O segundo princípio sugere proporcionar meios múltiplos de ação e de expressão (o "como" da aprendizagem), não somente diversificando os métodos de resposta e o percurso, mas também otimizando o acesso a instrumentos e tecnologias de apoio, além de oferecer opções para a expressão e a comunicação. Por fim, o terceiro princípio propõe viabilizar modos múltiplos de autodesenvolvimento (o "porquê" da aprendizagem). A afetividade é um elemento importantíssimo na aprendizagem assim como

\footnotetext{
2 CAST: organização multifacetada com a ambição singular de quebrar as barreiras de aprendizagem que milhões de pessoas experimentam todos os dias. Saiba mais em: https://www.cast.org/
} 
também a motivação e o envolvimento dos alunos (CAST, 2011 apud COSTA; PACHECO, 2018).

Em concordância e de maneira simplificada, a Revista Nova Escola 3 (2019, ed. 319) publicou uma reportagem na qual relata que, para ensinar ou aprender, é preciso ativar três áreas do cérebro: a rede de reconhecimento (o que aprender), a estratégica (como) e a afetiva (por que e para quê). É com base nessas premissas que o DUA se orienta e, mediante isso, provavelmente, mesmo sem saber, professores já tentaram aplicar esta metodologia no cotidiano escolar.

Em síntese, o DUA propõe aos docentes que suas práticas sejam o mais diversificadas possível, com materiais didáticos em formatos variados, conteúdos curriculares apresentados de múltiplas maneiras, mediação da aprendizagem e envolvimento dos educandos, relacionando o conteúdo com sua realidade. Essa abordagem extrapola o formato tradicional da sala de aula e pode cooperar para um modelo educacional mais atrativo, capaz de endossar o compromisso de garantir uma educação com equidade.

\section{Metodologia}

Quanto aos procedimentos técnicos aplicados na construção deste artigo utilizamos o estudo de caso que, segundo Gil (2006, p.54) é "uma modalidade de pesquisa amplamente utilizada nas ciências biomédicas e sociais. Consiste no estudo profundo e exaustivo de um ou poucos objetos, de maneira que permita seu amplo e detalhado conhecimento". Ainda de acordo com este autor, o estudo de caso vem sendo utilizado com frequência cada vez maior por contemplar pesquisas com diferentes fins, a saber:

a) explorar situações da vida real cujos limites não estão claramente definidos;

b) descrever a situação do contexto em que está sendo feita determinada investigação; e

\footnotetext{
${ }^{3}$ Como ser inclusivo desde o planejamento? Publicado na Revista NOVA ESCOLA, Edição 319, 01 de fevereiro de 2019. Disponível em: https://novaescola.org.br/conteudo/15226/comoser-inclusivo-desde-o-planejamento . Acesso em 18/02/2019.
} 
c) explicar as variáveis causais de determinado fenômeno em situações muito complexas que não possibilitam a utilização de levantamentos e experimentos. (GIL, 2008, p. 58)

Assim, o caso específico selecionado foi a adequação das práticas pedagógicas às deficiências dos alunos Público Alvo da Educação Especial (PAEE), unificando as práticas dos professores da sala de recursos a toda a equipe escolar, tendo como instituição de estudo uma unidade escolar da rede pública estadual de educação do Espírito Santo, localizada na região urbana do município Linhares/ES.

Foram considerados como sujeitos da pesquisa 37 (trinta e sete) servidores, sendo que 30 (trinta) deles responderam ao questionário, o equivalente a $81 \%$ da equipe docente. O presente estudo de caso foi realizado por meio de levantamento de dados quantitativos, no ano de 2018, de natureza descritiva, com sua posterior análise. Procuramos por informações que nos auxiliem na clareza do objeto de estudo e, para tanto, o instrumento utilizado para coletar os dados demanda confiabilidade e precisão. $O$ instrumento utilizado foi um questionário online, por meio da ferramenta "Formulários Google", aplicado aos sujeitos da pesquisa, para o levantamento das percepções dos profissionais que fazem parte do corpo docente. O formato online favoreceu não somente a aplicação, mas também a tabulação das respostas levantadas, devido à praticidade em levantar informações de forma rápida, confiável e eficiente dentro de um intervalo de tempo delimitado.

$O$ instrumento continha 13 (treze) questões objetivas e 3 (três) discursivas, elaboradas com a finalidade de conhecer não só as experiências pedagógicas dos sujeitos da pesquisa, acerca da educação inclusiva no locus da pesquisa, mas também suas demandas, anseios e expectativas, e coletou respostas durante o mês de novembro de 2018.

\section{Discussão de resultados}

As informações extraídas a partir do formulário foram fidedignas, uma vez que os profissionais responderam de maneira espontânea, sendo sua

\footnotetext{
${ }^{4}$ Saiba mais em <https://www.google.com/intl/pt-BR/forms/about/>.
} 
participação facultativa e anônima, o que permitiu uma análise criteriosa do real cenário educacional acerca da educação inclusiva.

Mapeamos, assim, os saberes e fazeres que integram a prática pedagógica dos professores que atuam com os alunos PAEE, a partir da experiência com a inclusão destes estudantes em classe regular na escola lócus da pesquisa.

Para contextualizar o perfil dos profissionais da unidade estudada, destacamos que, dentre os respondentes, $17 \%$ deles são servidores efetivos e $83 \%$ são contratados em regime de designação temporária (DT), o que pode ser entendido com um ponto de atenção, tendo em vista que tais professores não possuem a garantia de permanência na instituição, pois são contratados por meio de um edital, cuja vigência expira após um tempo determinado. Nesse sentido, é relevante que a equipe escolar fortaleça sua proposta inclusiva, de modo que a continuidade das práticas pedagógicas adotadas sejam garantidas com novos profissionais que venham a compor a equipe docente. No que se refere à formação acadêmica, $64 \%$ dos respondentes possuem especialização e 3\% mestrado, o que pode indicar a compreensão da importância de aprofundar o conhecimento de forma contínua como uma condição favorável para o desenvolvimento profissional.

O maior ponto de atenção observado na pesquisa foi a ausência do profissional da escola que atua na modalidade da educação especial entre os respondentes. Cabe, então, ao corpo gestor da escola refletir acerca dos marcos legais da educação especial, especialmente aqueles que tratam da atuação do professor que atua na sala de recursos. Cita-se, como exemplo, a Resolução MEC/CNE/CEB $n^{\circ} 4$, cujo artigo 13 versa sobre as atribuições do professor do AEE, no qual destacamos os incisos VI e VIII:

$\mathrm{VI}$ - orientar professores e famílias sobre os recursos pedagógicos e de acessibilidade utilizados pelo aluno; [...]

VIII - estabelecer articulação com os professores da sala de aula comum, visando à disponibilização dos serviços, dos recursos pedagógicos e de acessibilidade e das estratégias que promovem a participação dos alunos nas atividades escolares (BRASIL, MEC/CNE/CEB, 2009). 
A gestão escolar, associada ao corpo pedagógico, demanda meios de trazer o professor da sala de recursos para um trabalho alinhado e colaborativo ao desenvolvido nas classes regulares.

Segundo dados do censo escolar de 2017, disponíveis no portal QEdu 5 , existem 16 (dezesseis) alunos com deficiência matriculados na modalidade da educação especial na escola estudada, o que pode ser confirmado no Gráfico 1.

Gráfico 1 - Presença de alunos com deficiência nas turmas da escola estudada (2018)

Há alunos público-alvo da educação especial em suas turmas?

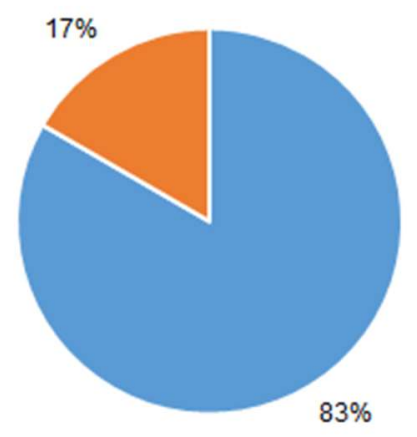

Fonte: Gráfico elaborado pela autora a partir de dados extraídos do formulário online aplicado aos servidores (2018).

O Gráfico 1 mostra que $83 \%$ dos professores respondentes relataram a presença de estudantes com deficiência em suas turmas, um quantitativo bastante significativo e que reflete a importância de um trabalho alinhado e em uma perspectiva inclusiva, por parte dos profissionais, oferecendo aos alunos PAEE o direito a uma educação de qualidade. Visando complementar essas informações, o percentual de estudantes com deficiência nas classes regulares pode ser observado no Gráfico 2.

${ }^{5}$ QEdu: portal público que contém informações acerca da qualidade do aprendizado em cada escola, município e estado do Brasil. Para mais informações, acesse: https://www.qedu.org.br/. 
Gráfico 2 - Percentual de alunos com deficiência nas turmas da escola estudada (2018)

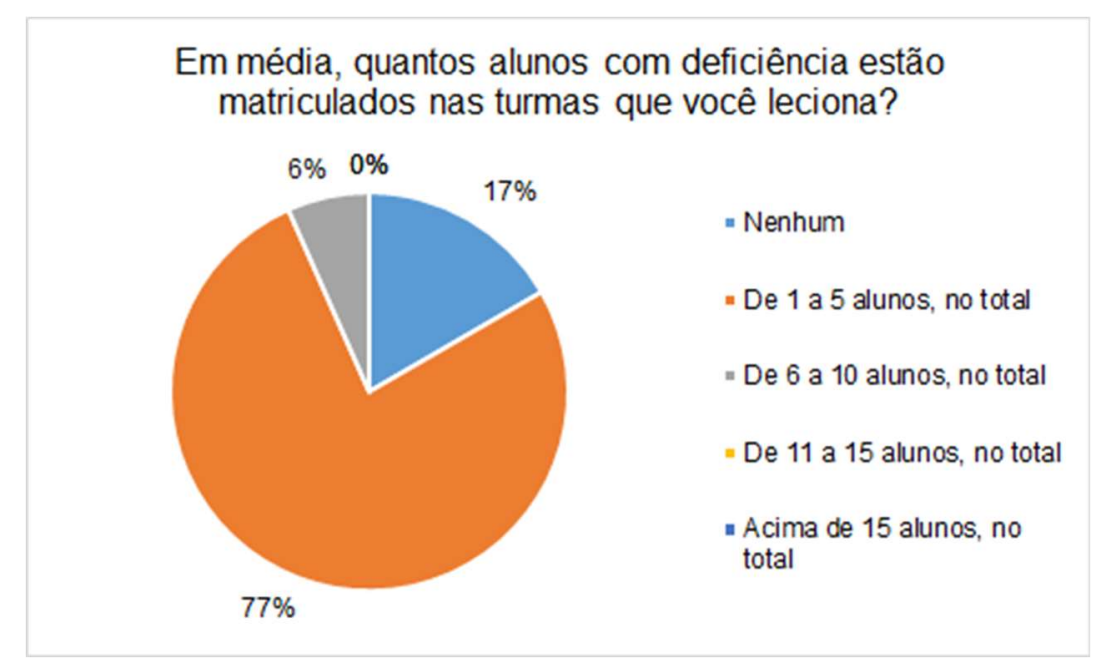

Fonte: Gráfico elaborado pela autora a partir de dados extraídos do formulário online aplicado aos servidores (2018).

Dentre os $83 \%$ de respondentes que informaram a presença de alunos PAEE em suas turmas, $77 \%$ deles disseram ter de 1 a 5 alunos com algum tipo de deficiência e $6 \%$ deles informaram que há de 6 a 10 educandos com deficiência matriculados em suas turmas.

Como o intento do estudo foi compreender acerca dos saberes e fazeres que integram a prática pedagógica na educação especial dos docentes que atuam na escola em foco, os professores também foram questionados acerca de suas dificuldades no trabalho com alunos PAEE. Assim, a percepção dos educadores pode ser apreciada no Gráfico 3. 
Gráfico 3 - Dificuldades dos profissionais que fazem parte do corpo pedagógico da escola estudada para trabalhar com alunos com deficiência (2018)

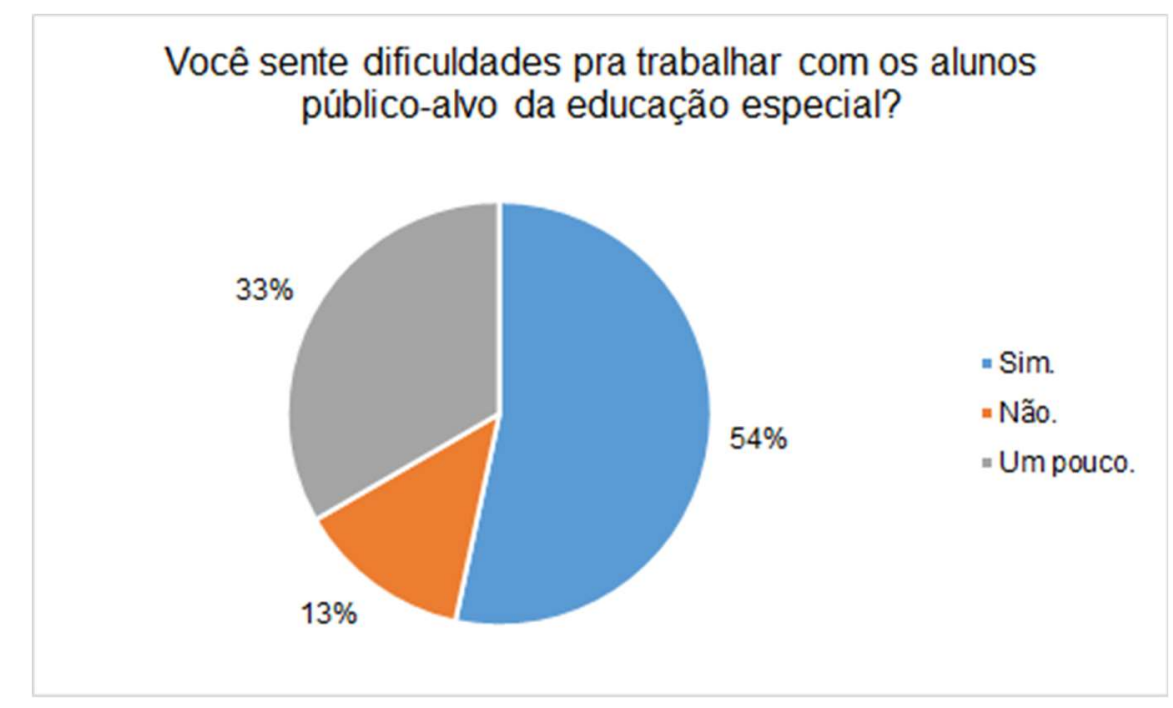

Fonte: Gráfico elaborado pela autora a partir de dados extraídos do formulário online aplicado aos servidores (2018).

Ao analisar as respostas do Gráfico 3, é possível observar que $87 \%$ dos respondentes relataram sentir alguma dificuldade no trabalho com os estudantes PAEE, sendo que: $54 \%$ deles responderam "Sim" e 33\% responderam sentir "Um pouco" de dificuldade.

Nesse viés, para a inclusão escolar efetivamente aconteça, torna-se necessário que algumas parcerias precisam sejam estabelecidas, ou seja, é preciso "[...] que o professor especialista e professor do ensino comum trabalhem em conjunto, que a equipe diretiva seja apoiadora desse processo e que a família seja o suporte necessário ao longo desse percurso" (ANTUNES; RECH; ÁVILA, 2016, p. 180).

As informações apresentadas nos Gráficos 1, 2 e 3 sugerem que as dificuldades dos profissionais poderiam ser amenizadas a partir do compartilhamento de experiências entre os docentes que atuam no ensino regular e o que atua na modalidade da educação especial, sob um viés formativo e colaborativo. O que nos remete ao ponto de atenção sinalizado anteriormente, onde destacamos a não participação do professor que trabalha com os alunos PAEE na pesquisa. 
Os professores também foram questionados acerca de suas participações em processos formativos direcionados à inclusão escolar. $O$ cenário encontrado pode ser visualizado no Gráfico 4.

Gráfico 4 - Participação dos profissionais em formações (2018)

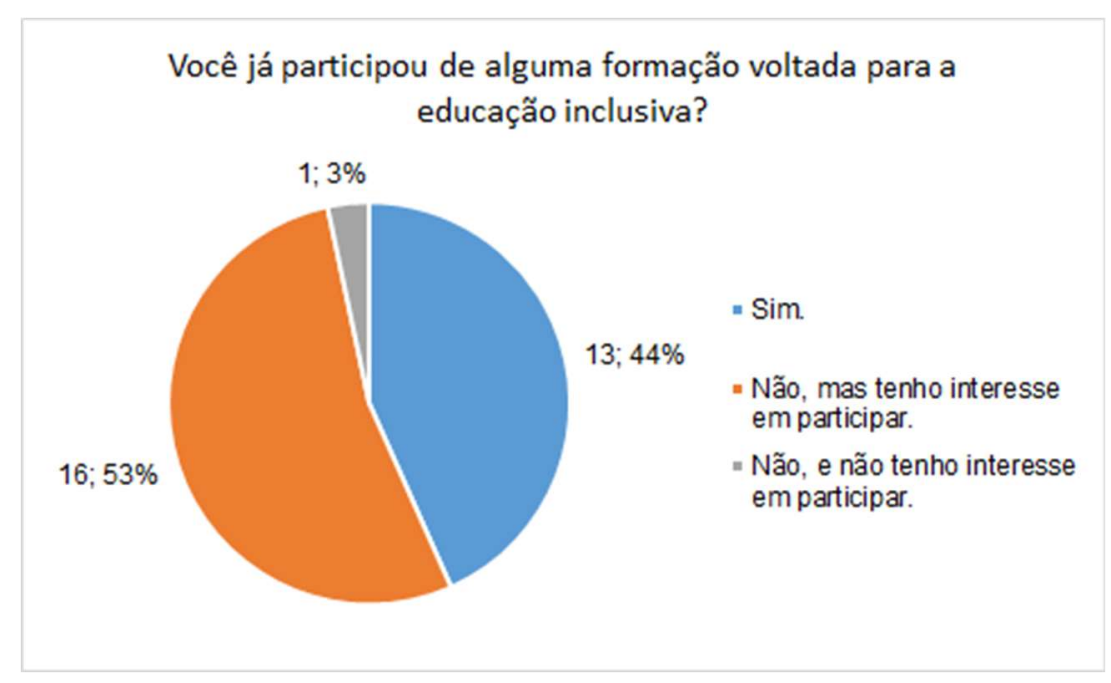

Fonte: Gráfico elaborado pela autora a partir de dados extraídos do formulário online aplicado aos servidores (2018).

As informações do Gráfico 4 revelam o interesse dos docentes pela formação acadêmica. Assim, tais resultados podem sugerir que uma proposta pedagógica na perspectiva inclusiva estará mais propensa ao êxito. Torna-se relevante, portanto, o fortalecimento de momentos destinados ao diálogo entre os professores do ensino regular e o professor da educação especial.

Indagamos aos investigados se intencionam participar de cursos que auxiliem no aprimoramento da prática docente no que se refere à sua atuação com os alunos com deficiência. As respostas encontradas foram bastante satisfatórias (Gráfico 5). 
Gráfico 5 - Intenção dos profissionais da escola em estudo de participarem de cursos (2018)

Você pretende realizar cursos que te ajudem a aprimorar sua prática docente em relação aos alunos com deficiência?

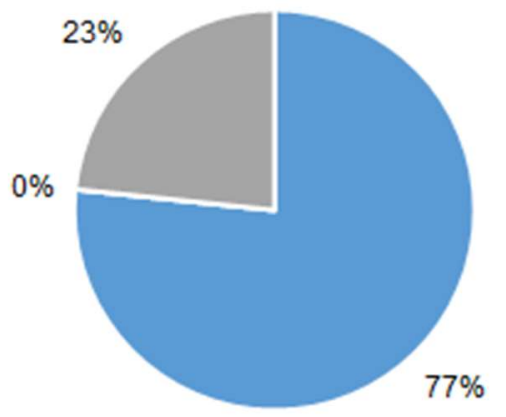

Fonte: Gráfico elaborado pela autora a partir de dados extraídos do formulário online aplicado aos servidores (2018).

O Gráfico 5 traz como principal ponto favorável o fato de que nenhum dos respondentes demonstrou ausência de intenção em realizar cursos que visam aperfeiçoar a prática pedagógica em relação aos alunos PAEE: $77 \%$ deles responderam positivamente e os demais se mostraram abertos a esta alternativa.

As questões discursivas do formulário online foram elaboradas com a intenção de conhecer as expectativas dos professores à luz da perspectiva do DUA, como estratégia para a inclusão escolar, tendo em vista as legislações que a amparam, de acordo com Prais e Rosa (2014, p. 369):

[...] os subsídios teóricos para a organização da atividade de ensino e dos princípios orientadores do desenho universal da aprendizagem ilustram o movimento de inclusão que visa a explicitar as intenções em práticas verdadeiramente inclusivas com caráter qualitativo do ensino e da aprendizagem de todos.

Assim, a primeira questão indagava aos educadores "Na sua opinião qual(is) fator(es) dificulta(m) o desempenho de uma efetiva educação inclusiva? Por que?", e foi elaborada para que pudéssemos compreender os principais entraves do grupo em relação à educação especial. 
Nas respostas coletadas, alguns respondentes pontuaram situações como: a escassez de recursos materiais; a infraestrutura inadequada nas escolas; a pouca, ou nenhuma, participação da família no processo educacional e, também, ao quantitativo de estudantes nas turmas. Contudo, o anseio dos professores por formações foi consenso, uma vez que mencionaram a dificuldade de trabalhar com o desconhecido, sugerindo que a falta de capacitação reflete na inaptidão para lidar com as diversidades do dia a dia. Destacamos, então, algumas respostas relevantes:

- Falta de conhecimento sobre o assunto. As escolas devem reconhecer a verdadeira importância da inclusão (sic).

- Penso que para garantir o processo de ensino aprendizagem, no que tange a EDUCAÇÃO INCLUSIVA faz-se necessária a garantia de aprimoramento dos profissionais, bem como o desenvolvimento de metodologias conceituadas direcionadas a este processo. Levo em consideração ainda, que tal prática fundamenta-se a partir da integração entre FAMíLIA, ALUNOS, ESCOLAS e SAÚDE, uma vez que esta prática exige a participação e o empenho de todos, sempre levando em consideração que esses elos são considerados de suma importância para os possíveis diagnósticos direcionados pela prática pedagógica visualizada no processo de ensinoaprendizagem e comportamental do alunado.

- Compreender o nível exato de abordagem de conteúdo para trabalhar em cada aluno e situação (sic).

- A falta de formação faz com que os professores se sintam desconfortáveis e consequentemente isso prejudica o processo de educação inclusiva (sic).

- Falta de salas apropriadas, de professores capacitados e de recursos pedagógicos. Porque é necessário ter professores capacitados para que se tenha um bom resultado, salas e recursos pedagógicos para atendê-los (sic) (FORMULÁRIO ONLINE, 2018, grifo nosso).

Quando relacionamos esses comentários com o elevado percentual de respostas nas questões objetivas que sinalizam 0 anseio por processos formativos, é possível crer que, mediante o exposto, uma ação formativa destinada à equipe, com foco na educação inclusiva terá um impacto pertinente. Ademais, tal fato pode, ainda, ser favorável para transformar esta ação na proposta pedagógica da escola, independente do quantitativo de 
professores DT ou do fluxo desses profissionais no quadro de funcionários da instituição de ensino.

A segunda questão foi pensada como um espaço para sugestões que poderiam enriquecer as práticas pedagógicas na escola pesquisada. Assim, foi perguntado aos docentes "Com base nas dificuldades relatadas, você gostaria de sugerir algo?". A maior parte dos professores respondentes manifestou desejo de formação na área e pontuou a necessidade de mais diálogo entre os docentes. Ressaltamos as seguintes respostas:

- Que a inclusão seja discutida na escola como fator relevante (sic). - Produção de materiais de apoio em suas diversas possibilidades (sic).

- Pedagogos CAPACITADOS de forma especializada na Educação inclusiva levando em consideração o NORTEIO E FORMAÇÃO DOS DOCENTES INEXPERIENTES (sic).

- Maior qualificação dos profissionais, através de cursos disponibilizados pelos órgãos competentes (sic).

- Fazer reunião com as partes interessadas (sic) (FORMULÁRIO ONLINE, 2018, grifo nosso).

Tais respostas endossam o fato de que uma ação formativa, desenhada em uma perspectiva inclusiva, destinada aos profissionais que atuam com os alunos PAEE, pode ser de grande valia quando bem orientada e planejada.

Além disso, percebemos que há, também, manifestações favoráveis à produção de materiais que tenham diversas finalidades, assim como defende a proposta do DUA.

A terceira e última questão foi destinada a comentários, apresentando o seguinte enunciado: "Se desejar, relate brevemente sua experiência com a educação inclusiva em suas aulas". Muitos professores relataram suas vivências, tais como:

- Busco sempre trabalhar a inclusão com o restante dos alunos e trabalhar atividades diversificadas que atendam toda a turma (sic).

- Haja vista pouca experiência especificamente nessa prática, diria que aprendi muito com meus alunos. Foram desafios importantes para meu aprimoramento pedagógico, haja vista que não tive experiências anteriores (sic). 
- Tornou-se honroso lidar com tal prática, sempre se relacionando a equipe e demais profissionais para desenvolvermos com sucesso, buscando de materiais diferenciados para o bom desenvolvimento do processo de ensino-aprendizagem (sic).

- Foi de grande valia, pois, em cada aula o aprendizado e o aprimoramento das metodologias foi identificado (sic).

- Não sei bem como lidar, pois tenho pouco conhecimento sobre como trabalhar com a deficiência que meu aluno apresenta (sic) (FORMULÁRIO ONLINE, 2018).

Os fragmentos apresentados nos levaram a perceber o anseio dos professores em atuar com competência e proporcionar uma educação inclusiva de qualidade, estabelecendo uma relação de mútua aprendizagem com o aluno PAEE. Ademais, percebemos que alguns educadores sinalizaram o desejo de que a inclusão seja "para todos" e não somente para o aluno PAEE.

Os resultados aqui destacados endossam a relevância de se fazer cumprir as diversas legislações vigentes, no intento de ofertar a educação para todos. Nessa perspectiva, Antunes, Rech e Ávila, destacam o papel articulador do pedagogo a partir da Política Nacional de Educação Especial na Perspectiva da Educação Inclusiva, ressaltando que este documento "trouxe a necessidade de articular o trabalho do pedagogo com o do professor especialista, já que a inclusão escolar precisa ser responsabilidade de toda a comunidade escolar" (ANTUNES; RECH; ÁVILA, 2016, p. 177).

Em síntese, ao compararmos as respostas objetivas analisadas por meio dos gráficos com as informações das respostas discursivas, notamos o elevado percentual de manifestações que sinalizam o anseio dos docentes por processos formativos para a educação especial, o que confirma a relevância da temática em prol da inclusão de todos os estudantes. No entanto, para alcançar o sucesso em qualquer proposta pedagógica, é primordial o entendimento que não basta participar de momentos formativos ou dialógicos se os conhecimentos adquiridos não forem aplicados. 


\section{Conclusão}

Perante o cenário apresentado, torna-se relevante que a equipe escolar estabeleça espaços educacionais adequados a todos os alunos, com ou sem deficiência, levando em consideração suas peculiaridades e tempos de aprendizagem, de forma a estimular seu desenvolvimento. Assim, concluímos que a construção dos saberes dos docentes necessita ser direcionada para uma formação fundamentada na heterogeneidade existente nas escolas, dentro de uma perspectiva inclusiva.

Cabe destacar que a abordagem do DUA reflete em um modelo prático que almeja oportunizar mais aprendizagens aos discentes, por meio de um planejamento pedagógico contínuo, tendo em vista a necessidade de preencher as lacunas que envolvem a educação especial. Ressalta-se, também, que é dever do Estado garantir a educação para todos, conforme preconizam os marcos legais da educação especial, visando educar de maneira inclusiva e com equidade.

Por fim, entendemos ser relevante e urgente que a escola repense sua proposta pedagógica, com o intento de encontrar meios para aperfeiçoá-la e proporcionar uma educação inclusiva, uma vez que, a equipe escolar da unidade de ensino estudada mostrou-se aberta para momentos formativos e de compartilhamento de experiências, com vistas a se apropriar de conceitos e metodologias voltadas para processo da efetiva inclusão escolar. Nessa perspectiva, a abordagem do DUA pode ser compreendida como uma aliada a este processo, uma vez que seu objetivo central foca na construção de práticas pedagógicas acessíveis para a aprendizagem de todos os alunos presentes nas salas regulares. Tais práticas serão elaboradas a partir de um trabalho colaborativo realizado entre professor da sala de recursos e os demais docentes do ensino regular.

\section{Referências}

ANTUNES, H. S.; RECH, A. J. D.; ÁVILA, C. C. Educação inclusiva e formação de professores: desafios e perspectivas a partir do Pacto Nacional pela Alfabetização na Idade Certa. Revista Práxis Educativa. Vol. 11, $\mathrm{n}^{0} 1$, janeiro/abril 2016. ISSN 1809-4309. 2016. Disponível em: 
http://www.revistas2.uepg.br/index.php/praxiseducativa/article/view/8162.

Acesso em: 10 out. 2020.

BRASIL. Constituição (1988). Constituição da República Federativa do Brasil. Disponível em: http://www.planalto.gov.br/ccivil_03/Constituicao/Constituicao.htm. Acesso em: 2 out. 2020.

BRASIL. Convenção sobre os Direitos das Pessoas com Deficiência: Protocolo Facultativo à Convenção sobre os Direitos das Pessoas com Deficiência. 2007.

BRASIL. Decreto $n^{\circ} 3.298$, de 20 de dezembro de 1999. Dispõe sobre a Política Nacional para a Integração da Pessoa Portadora de Deficiência, consolida as normas de proteção, e dá outras providências. Diário Oficial da União, Brasília, DF, 21 dezembro de 1999. Disponível em: http://www.planalto.gov.br/ccivil_03/decreto/d3298.htm. Acesso em: 3 out. 2018.

BRASIL. Decreto $n^{\circ} 3.956$, de 8 de outubro de 2001. Promulga a Convenção Interamericana para a Eliminação de Todas as Formas de Discriminação contra as Pessoas Portadoras de Deficiência. Diário Oficial da União, Brasília, DF, 8 de outubro de 2001.2 Disponível em: http://portal.mec.gov.br/seesp/arquivos/pdf/guatemala.pdf. Acesso em: 10 out. 2020.

BRASIL. Decreto $\mathrm{n}^{\circ}$ 6.094, de 24 de abril de 2007. Dispõe sobre a implementação do Plano de Metas Compromisso Todos pela Educação, pela União Federal, em regime de colaboração com Municípios, Distrito Federal e Estados, e a participação das famílias e da comunidade, mediante programas e ações de assistência técnica e financeira, visando a mobilização social pela melhoria da qualidade da educação. Disponível em: http://www.planalto.gov.br/ccivil_03/_ato2007-2010/2007/decreto/d6094.htm. Acesso em: 20 out. 2020.

BRASIL. Decreto Legislativo $\mathrm{n}^{\circ} 186$, de 9 de julho de 2008. Aprova o texto da Convenção sobre os Direitos das Pessoas com Deficiência e de seu Protocolo Facultativo, assinados em Nova lorque, em 30 de março de 2007. Disponível em: http://www.planalto.gov.br/ccivil_03/Congresso/DLG/DLG-186-2008.htm. Acesso em: 20 out. 2020.

BRASIL. Decreto $n^{0} 7.611$, de 17 de novembro de 2011. Dispõe sobre a educação especial, o atendimento educacional especializado e dá outras providências. Disponível em: http://www.planalto.gov.br/ccivil_03/_ato20112014/2011/decreto/d7611.htm. Acesso em: 12 out. 2020.

BRASIL. Decreto $n^{\circ} 7.612$, de 17 de novembro de 2011. Institui o Plano Nacional dos Direitos da Pessoa com Deficiência - Plano Viver sem Limite. Disponível em: http://www.planalto.gov.br/ccivil_03/_ato20112014/2011/decreto/d7612.htm. Acesso em: 12 out. 2020. 
BRASIL. Decreto $n^{\circ} 7.750$, de 8 de junho de 2012. Regulamenta o Programa Um Computador por Aluno - PROUCA e o Regime Especial de Incentivo a Computadores para Uso Educacional - REICOMP. Disponível em: http://www.planalto.gov.br/ccivil_03/_Ato2011-2014/2012/Decreto/D7750.htm. Acesso em: 13 out. 2020.

BRASIL. Lei $n^{\circ}$ 9.394, de 20 de dezembro de 1996. Estabelece as diretrizes e bases da educação nacional. Disponível em: http://www.planalto.gov.br/Ccivil_03/leis/L9394.htm. Acesso em: 3 out. 2020.

BRASIL. Lei $\mathrm{n}^{\circ}$ 10.436, de 24 de abril de 2002. Dispõe sobre a Língua Brasileira de Sinais - Libras e dá outras providências. Disponível em: http://www.planalto.gov.br/ccivil_03/leis/2002/l10436.htm. Acesso em: 9 out. 2020.

BRASIL. Portaria $n^{0} 1.793$, de dezembro de 1994. Dispõe sobre a necessidade de complementar os currículos de formação de docentes e outros profissionais que interagem com portadores de necessidades especiais e dá outras providências. Disponível em: http://portal.mec.gov.br/seesp/arquivos/pdf/port1793.pdf. Acesso em: 9 out. 2020.

COSTA, E. L. DA.; PACHECO, D. P. Desenho universal para aprendizagem e a acessibilidade dos livros didáticos de química. Revista Gestão Universitária. 2018. Disponível em: http://www.gestaouniversitaria.com.br/artigos/desenhouniversal-para-aprendizagem-e-a-acessibilidade-dos-livros-didaticos-dequimica. Acesso em: 6 de out. de 2020.

Desenho Universal para Livros Didáticos. Oficina Brasileira - Desenho Universal para Livros Didáticos. Manual do Desenho Universal para Aprendizagem elaborado pelo Movimento Down. Disponível em: http://www.movimentodown.org.br/wp-content/uploads/2015/08/Manual-FINALbibliografia.pdf. Acesso em: 25 set. 2020.

GIL, A. C. Métodos e técnicas de pesquisa social. $4^{a}$ ed. São Paulo, SP: Atlas, 2008.

GIL, A. C.. Como elaborar projetos de pesquisa. $4^{a}$.ed. 8. reimp. São Paulo: Atlas, 2006.

JESUS, D. M. de; ALMEIDA, M. L.; SOBRINHO, R. C. Pesquisa-açãocríticocolaborativa: implicações para a formação continuada e a inclusão escolar. In: REUNIÃO ANUAL DA ANPED: 40 anos de Pós-Graduação em Educação no Brasil, 25, 2005, Caxambu. Anais... Caxambu/MG: Anped, 2005.

NOVA ESCOLA. Como ser inclusivo desde o planejamento?. Revista Nova Escola. Edição 319, 01 de fevereiro de 2019. Disponível em: https://novaescola.org.br/conteudo/15226/como-ser-inclusivo-desde-oplanejamento. Acesso em: 27 set. 2020. 
PLETSCH, M. D.; SOUZA, F. F. DE; ORLEANS; L. F. A diferenciação curricular e o desenho universal na aprendizagem como princípios para a inclusão escolar. Revista Educação e Cultura Contemporânea. Vol. 14, № 35, p. 264281, 2017. Universidade Estácio de Sá. Programa de Pós-graduação em Educação.

http://periodicos.estacio.br/index.php/reeduc/article/viewArticle/3114. Acesso em: 20 out. 2020.

PRAIS, J. L. S.; ROSA, V. F. Organização da atividade de ensino a partir do desenho universal de aprendizagem: das intenções às práticas inclusivas. Revista Polyphonía. Vol. 25(2), p. 359-374, 2014. Programa de Pósgraduação em Ensino e Educação Básica do CEPAE/Universidade Federal de Goiás. Goiânia, GO, 2014.

UNESCO. Declaração de Salamanca. Disponível em: https://unesdoc.unesco.org/ark:/48223/pf0000139394. Acesso em: 27 set. 2020.

ZERBATO, A. P.; MENDES, E. G. Desenho universal para a aprendizagem como estratégia para a inclusão escolar. Revista Educação Unisinos. Vol. 22(2), p. 147- 155, 2018. Universidade do Vale do Rio dos Sinos. São Leopoldo, RS, 2020.

\section{Sobre os Autores}

\section{Alessandra Boldrini Monechi}

alessandra.boldrini@hotmail.com

Pedagoga e Professora de história, nascida em 18/08/1974, em Colatina/ES. Mestre em Ciência, Tecnologia e Educação (Faculdade Vale do Cricaré) e pós graduada em administração, educação de jovens e adultos e educação infantil e séries iniciais

\section{Luana Guisso}

lfgd10@hotmail.com

Possui Graduação em Licenciatura Plena em Pedagogia com Habilitações em: Supervisão Escolar, Educação Infantil e Magistério das Séries Iniciais do Ensino Fundamental, pela Faculdade de Ciências Humanas de Aracruz (2001). Doutoranda em História Social das Relações Políticas pela UFES Universidade Federal do Espírito Santo. Mestre em Educação Ambiental pela Faculdade de Aracruz. Especialista pela Faculdade de Ciências Humanas de Aracruz em: Psicopedagogia, Gestão de Recursos Humanos e Pedagogia Empresarial. Atualmente é Coordenadora Adjunta do Mestrado Profissional em Ciência, Tecnologia e Educação Regional da Faculdade Vale do Cricaré de São Mateus (ES), Professora de Didática Geral do curso superior de Educação Física e Pedagogia e Educação das Relações Étnico-Raciais do curso superior de Engenharia de Produção todos da Faculdade Vale do Cricaré de São Mateus (ES). 